\title{
A atuação de Silas Malafaia contra o PLC 122: análise de suas páginas no Twitter e no Facebook
}

\author{
La actuación de Silas Malafaia contra el PLC 122: \\ análisis de sus páginas enTwitter y Facebook
}

\section{The performance of Silas Malafaia against PLC 122: analysis of his pages on Twitter and Facebook}

\author{
Márcia Zanin Feliciani' \\ Leandra Cohen Schirmer" \\ Aline Roes Dalmolin"II
}

Palavras chave:

Resumo:

O PLC 122/2006 foi uma proposta de lei criada pela deputada lara Bernardi com o objetivo de criminalizar atos de violência física e/ou simbólica referentes a sexualidade e gênero. Grupos conservadores posicionaram-se fortemente em contrariedade à aprovação do projeto, alegando que o mesmo feria os valores da família, da Constituição

Silas Malafaia (no que tange à liberdade de expressão) e da Bíblia - que, segundo determinadas leituras, consideraria a homossexualidade pecaminosa.

PLC 122 Percebemos Silas Malafaia, líder da Igreja Assembleia de Deus

Twitter

Facebook Vitória em Cristo, como uma das personalidades mais atuantes nesse processo; assim, a partir dos conceitos de empreendedorismo moral (BECKER, 2008), campo social e, mais especificamente, campo religioso (BOURDIEU, 1983; 2008), midiatização e circulação

Empreendedorismo moral (BRAGA, 2012), buscaremos compreender a atuação do pastor com relação aos desdobramentos que se seguiram à proposta. Terse-á como objeto as postagens feitas em seus perfis no Twitter e no Facebook nos anos de 2011 e 2012 - período em que as discussões sobre o PLC intensificaram-se. 


\begin{abstract}
Resumen:
EI PLC 122/2006 fue una propuesta de ley creada por la diputada lara Bernardi con el objetivo de criminalizar actos de violencia física y/o simbólica referentes a sexualidad y género. Los grupos conservadores se posicionaron fuertemente en contra de la aprobación del proyecto, alegando que el mismo dañaba los valores de la familia, de la Constitución (en lo que se refiere a la libertad de expresión) y de la Biblia, que según ciertas lecturas, consideraría la homosexualidad pecaminosa. Percibimos a Silas Malafaia, líder de la Iglesia Asamblea de Dios Victoria en Cristo, como una de las personalidades más actuantes en ese proceso. En este sentido, a partir de los conceptos de emprendedor moral (BECKER, 2008), campo social y, más específicamente, campo religioso (BOURDIEU, 1983; 2008) y mediatización y circulación (BRAGA, 2012), buscaremos comprender la actuación del pastor con respecto a los desdoblamientos que siguieron a la propuesta. Se tendrán como objeto las entradas hechas en sus perfiles en Twitter y Facebook en 2011 y 2012, período en que las discusiones sobre el PLC se intensificaron.

\section{Palabras clave:}

Silas Malafaia

PLC 122

Twitter

Facebook

Empreendedorismo moral
\end{abstract}

\section{Keywords:}

Silas Malafaia

PLC 122

Twitter

Facebook

Moral entrepreneurship

\section{Abstract:}

PLC 122/2006 was a bill proposed by deputy lara Bernardi with the aim of criminalizing acts of physical and/or symbolic violence related to sexuality and gender. Conservative groups strongly opposed the bill, claiming that it violated the values of the family, the Constitution (in terms of freedom of expression) and the Bible - which, according to certain readings, would consider homosexuality as sinful. We perceive Silas Malafaia, leader of the Church of the Assemblies of God Victory in Christ, as one of the most active personalities in this process. Thus, from the concepts of moral entrepreneurship (BECKER, 2008), social field and, more specifically, religious field (BOURDIEU, 1983; 2008) and mediatization and circulation (BRAGA, 2012), we will seek to understand the pastor's performance in relation to developments that followed the proposal. We'll take as object the posts madden in his profiles on Twitter and Facebook in 2011 and 2012 - a period when discussions about the PLC intensified. 


\section{A atuação de Silas Malafaia contra o PLC 122: análise de suas páginas no Twitter e no Facebook}

\section{Introdução}

As igrejas pentecostais ganharam força no Brasil a partir do século XX, com a separação entre a Igreja Católica e o Estado. De lá para cá, seu crescimento foi exponencial: no censolv realizado em 2010 pelo Instituto Brasileiro de Geografia e Estatística (IBGE), cerca de 25 milhões de brasileiros disseram-se membros de alguma congregação pentecostal.

A presença desses adeptos, entretanto, não fica restrita aos espaços religiosos: na mídia, percebemos essas congregações ocupando considerável espaço (principalmente no rádio, na televisão e na internet), permitindo o alcance a uma parcela ainda maior da população; na política, vê-se uma bancada religiosa composta por líderes evangélicos de vários partidos, em grande parte adeptos da direita conservadora brasileira.

Esse último ponto destaca-se por motivar a tensão contínua entre religião e Estado. Ainda que não seja autorizado por lei que ninguém imponha sua crença aos demais e que nenhum grupo possa tornar suas leis religiosas parte integrante das leis civis, na prática não é o que ocorre, justamente em função da presença desses grupos nas mais diferentes instâncias governamentais. O artigo 18 da Declaração dos Direitos Humanos prescreve que:

Toda pessoa tem direito à liberdade de pensamento, consciência e religião; este direito inclui a liberdade de mudar de religião ou crença e a liberdade de manifestar essa religião ou crença, pelo ensino, pela prática, pelo culto $\mathrm{e}$ pela observância, isolada ou coletivamente, em público ou em particular. (ONU, 1948)

A prescrição, entretanto, não parece bem clara para alguns religiosos - que confundem essa "livre manifestação da religião" com uma liberdade de expressão sem limites. Por conta disso, muitos temas que mobilizam a opinião pública e que, inicialmente, seriam pautados no campo político, acabam sendo discutidos e muitas vezes sofrem influência do campo religioso - como as pesquisas com células-tronco, a eutanásia, os direitos sexuais e reprodutivos e, claro, questões ligadas à homossexualidade. O último é constantemente abordado nos discursos de atores religiosos, que utilizam argumentos contrários à prática.

Silas Malafaia, líder da Igreja Assembleia de Deus Vitória em Cristo, é conhecido por ter uma opinião bastante marcada a respeito do tema. O pastor vem se caracterizando, nos últimos anos, como uma "celebridade midiática evangélica, que assume o papel da pessoa controvertida e constrói sua imagem como 'aquele que diz as verdades'" (CUNHA, 2014b, p. 9). Um dos vários casos de divergências entre Silas e os grupos LGBTTQIA ${ }^{\vee}$ foi a respeito do Projeto de Lei da Câmara $n$. 122/2006 - ou, como ficou mais conhecida, a lei anti-homofobia.

No Brasil, a lei 7.716/89 tipifica criminalmente a prática de discriminação devido a raça, cor, etnia, procedência nacional ou religião. Contudo, a legislação não prevê punição específica para vários tipos de discurso de ódio - como é o caso de preconceito em função de gênero e orientação sexual -, nem mesmo prescreve penas mais duras em casos de violência física ou até homicídio derivado de intolerância. Nesses casos, a saída legalmente encontrada no judiciário vem sendo enquadrar criminalmente os casos de dis- 
criminação como "abuso de direito", pela falta de uma regulamentação específica para esses crimes.

O PLC 122, então, foi proposto em 2006 pela deputada lara Bernardi no sentido de suprir essa lacuna. Uma das principais justificativas para a aprovação da lei, além do próprio combate à violência homofóbica, seria o de incluir na legislação brasileira uma tipificação para a punição da violência simbólica contra a população LGBTTQIA, ampliando a abrangência das leis já existentes.

Apesar de proposto em 2006, as discussões acerca do projeto intensificaram-se entre 2011 e 2012, período em que houve audiências públicas para discussão do tema. Malafaia, convidado a participar dos debates como representante contrário à aprovação do projeto, apresentou diversos argumentos para defender sua posição - como o de que o projeto fere os valores da família tradicional e o direito de expressão dos indivíduos discordantes da prática homossexual.

Além de manifestar sua opinião publicamente, o pastor promoveu uma campanha efetiva contra a aprovação da lei, incentivando seus fiéis a participar de um abaixo-assinado e de uma manifestação em Brasília, além de exercer pressão junto aos parlamentares e à imprensa - investidas que acabaram por fazer dele "ator político e maior representante dos grupos evangélicos conservadores" (CAMPOS, GUSMÃO e MAURICIO JR., 2015, p. 168) no contexto atual.

A este estudo, cabe identificar a mobilização do pastor e de seus seguidores a respeito do PLC a partir de seus perfis oficiais no Facebook e no Twitter, durante os anos de 2011 e 2012. A análise do perfil do Twitter busca compreender o ativismo do pastor a partir de seus próprios tweets, enquanto a do Facebook enfoca a circulação midiática (BRAGA, 2012) percebida nos comentários dos interagentes. Através de análise discursiva, busca-se compreender o papel de Silas como empreendedor moral (BECKER, 2008), bem como observar sua atuação nos campos político, religioso e midiático.

\section{Circuitos entre os campos religioso, político e midiático}

Campo, segundo Bourdieu (1983), refere-se a um espaço estruturado por posições sociais e responsável por estruturá-las. Resumidamente, trata-se de um jogo, no qual os agentes lutam entre si pelo domínio do respectivo capital - que é específico em cada campo.

No caso do campo religioso, a movimentação do capital está ligada tanto a fatores internos quanto externos. É perceptível a relação existente entre as crenças e seu contexto social: o próprio desenvolvimento e institucionalização do campo religioso como tal estão ligados ao crescimento das cidades (BOURDIEU, 1983).

É importante destacar que o campo religioso não é homogêneo, sendo composto por uma infinidade de crenças com diferentes denominações, procedências e objetivos. Só no Brasil, através do censo realizado pelo IBGE em 2000, constatou-se o surgimento de mil e duzentas novas denominações religiosas em comparação à pesquisa anterior, de 1991 (CAMPOS, 2004). Segundo Bourdieu (2008), isso seria um reflexo da principal característica de tal campo: a concorrência.

Dentro das instituições religiosas também não há homogeneidade: existem diferentes perfis de membros. Há os leigos (ou simples adeptos), de conhecimento mais básico, e os dominantes, detentores de parte significativa do capital em circulação no campo. São esses que, através de 
seus discursos e do uso do carisma, são capazes de mobilizar os demais em benefício das causas de seu interesse, despertando neles a necessidade de aliar-se a elas (BOURDIEU, 2008).

Tal mobilização é perceptível na relação dos evangélicos com a política, que é cada vez mais latente no país. A influência exercida pelas lideranças nos membros de congregações evangélicas é maior por vários fatores, dentre eles a baixa renda e escolaridade de boa parte dos fiéis e, principalmente, a grande exposição argumentativa a que estes são submetidos, visto que a maior parte deles pratica atividades religiosas frequentemente (MAIA, 2006).

Com a entrada das personalidades religiosas na política, a influência passou a se dar no sentido de conquistar, além de fiéis, eleitores. Para isso, são dois os tipos de argumentos utilizados pelas lideranças: os efetivamente religiosos, que consideram os problemas políticos como uma guerra espiritual e defendem que só a presença de homens de Deus naquele meio pode ser uma solução (MAIA, 2006), e os derivados de outros campos, como o jurídico e o científico, como vemos no caso de Malafaia. Recorre-se, neles, a valores dos quais pessoas que não participam do campo religioso também compartilham, legitimando seus posicionamentos diante de um público mais amplo do que apenas o de seus fiéis.

A legitimidade conquistada dentro dos campos religioso e político possibilitam a ampliação do capital econômico dessas instituições; a soma dos três, por consequência, permite o seu acesso à mídia, multiplicando, ainda mais, o alcance dos discursos religiosos. Esse contexto de intensa disputa pelos fiéis, não raro é articulado a partir de estratégias de marketing, publicização e segmentação características do campo midiático, sobretudo por parte das igrejas neopentecostais, de modo que não é estranho ao contexto atual observarmos no Brasil o fracionamento de igrejas não por cismas doutrinários, como ocorria no passado, mas sobretudo na orientação por atingir um determinado público-alvo.

A presença dessas instituições na esfera midiática não é algo novo, mas vem sendo cada vez mais visível. Há canais de TV criados e mantidos única e exclusivamente para a divulgação de crenças específicas, como a Rede Vida (da Igreja Católica), a RIT (da Igreja Internacional da Graça de Deus), o canal Novo Tempo (da Igreja Adventista do Sétimo Dia), etc. - todos com programações regadas a cultos, programas de pastores, clipes musicais, etc.

O que desperta mais a atenção, entretanto, é como a religião tem-se feito presente nas grandes emissoras. A Rede Record, liderada pelo bispo neopentecostal Edir Macedo, tem feito uma verdadeira revolução em termos de conteúdo - transformando episódios bíblicos até em telenovelas. A própria Rede Globo tem aberto espaço para a religião: um exemplo é a organização e transmissão anual do Festival Promessas, que reúne shows de diversos artistas gospel. Ainda, para além da presença em mídias tradicionais, também cresce o uso da internet por personalidades religiosas: páginas em redes sociais como Facebook e Twitter, vídeos de pregações no Youtube e até portais de notícias exclusivos, alcançando um número cada vez maior de seguidores.

Segundo Cunha (2014a), essa é uma resposta da religião ao capitalismo. A ligação entre mídia religiosa e mercado, caracterizada pela autora como cultura gospel, é cada vez mais latente, e se sustenta principalmente pela tríade entre música, mercado e entretenimento.

Essas transformações são consequência da midiatização, conceituada 
por Braga (2012, p. 35) como uma série de processos que "não se restringem ao objeto "meios" nem ao objeto "receptores esuas mediações", mas os incluem, a ambos, em formações muitíssimo diversificadas e ainda articulados a outras formações". Foi a partir dessas transformações complexas que "todas as áreas e setores da sociedade passaram a desenvolver práticas e reflexões sobre sua interação com as demais áreas e setores" (BRAGA, 2012, p. 37) - o que explica a tentativa de adaptação da religião às diversas formas de comunicação.

É a midiatização, portanto, que pauta a atuação dos diferentes atores religiosos para adentrar nas lógicas do campo midiático. No contexto atual do campo evangélico brasileiro, observamos uma verdadeira 'guerra' por visibilidade (CUNHA, 2013), tanto por parte dos leigos quanto dos dominantes - usando a terminologia bourdiana -, nas quais se enquadram disputas simbólicas travadas com estratégias advindas de ambos os campos. Nessa guerra, salientam-se as disputas em torno de questões referentes à ingerência sobre a vida humana e a sexualidade.

Nesse contexto belicoso, muitos líderes religiosos evangélicos, qualificados de considerável capital simbólico nas trincheiras de suas denominações religiosas, lançam-se no campo midiático atuando como 'profetas' (BOURDIEU, 2008), tendo que conquistar simpatizantes pela manipulação simbólica. Nessa categoria poderíamos enquadrar lideranças religiosas como Edir Macedo, Marco Feliciano e o próprio Silas Malafaia.

São lideranças carismáticas capazes de mobilizar uma quantidade considerável de pessoas, inclusive as que não fazem parte do campo religioso. Isso se dá pela semelhança entre as visões de mundo desses sujeitos, normalmente liga- das à moral e aos 'bons costumes'. A atuação dessas lideranças, que muitas vezes atingem o status de celebridade midiática, podem ser observadas a partir do conceito de empreendedor moral (BECKER, 2008).

\section{A atuação de Silas Malafaia como empreendedor moral}

Empreendedores morais, segundo Becker (2008), são líderes de opinião, que podem criar ou impor regras de comportamento de acordo com o que julgam formas certas ou erradas de viver e pensar, influenciando as pessoas ao seu redor a agir da mesma forma. O empreendedor caracterizado como criador de regras "está interessado no conteúdo das regras. [...] Ele julga que nada pode estar certo no mundo até que se façam regras para corrigi-Io" (BECKER, 2008, p. 153); em resumo, podem ser chamados de autores das ditas regras.

Já os impositores, segundo tipo de empreendedores morais, são os responsáveis por transmitir de geração em geração as regras que são criadas pelos sujeitos e instituições sociais (os criadores), e sua atuação faz com que boa parte delas acabem intrínsecas em nosso senso comum. São eles que garantem que as regras de autoria dos criadores estejam sendo cumpridas.

À primeira vista, enquadramos Malafaia como um impositor, visto que seus discursos baseiam-se em 'regras' já dadas e consolidadas - ou a partir da Bíblia, ou da Constituição. Entretanto, observando atentamente sua atuação, é possível repensar essas categorias propostas por Becker.

Sabe-se que a base do discurso religioso do pastor é a Bíblia. A obra, entretanto, possui séculos de existência, tendo sido escrita em circunstâncias completa- 
mente diferentes da conjuntura mundial atual. Ao lê-la, deve-se lembrar, portanto, que o texto "não constitui, acima dos acontecimentos, e em um universo inalterável, uma estrutura intemporal; define-se como o conjunto das regras que caracterizam uma prática discursiva" (FOUCAULT, 2008, p. 145).

Ou seja: não se pode, simplesmente, considerar o texto como verdade absoluta, nos dias de hoje, sem considerar as condições anteriores nas quais ele foi escrito. É exatamente o contrário que se percebe em Malafaia, que, ao fazer sua leitura da obra, "ignora interpretações que relativizam o contexto histórico da época na qual os textos foram escritos" (FELICIANI; DALMOLIN, 2016, p. 6).

Se considerarmos tal contexto, a interpretação de Silas (e de qualquer outro indivíduo que realizar a leitura da obra) pode não ser correta, ou, pelo menos, não estar de acordo com a ideia imaginada originalmente. Pensando dessa forma, Malafaia poderia ser visto como um reformulador dessas regras, já que, apesar de basear-se em 'regras' pré-determinadas, o pastor interpreta-as a partir de sua visão de mundo.

Além disso, precisamos analisar a situação por outro olhar, pensando no contexto de midiatização no qual estamos inseridos. É notável que, dependendo do público e do meio, o discurso dos empreendedores é diferente. Usando a terminologia bourdiana, tais ações alteram-se de acordo com o campo em questão.

Segundo Rodrigues (2000), cada campo social detém um regime de simbólica própria, que pode ser formal ou informal. A simbólica formal caracteriza-se pelo rigor de sua manifestação e seu uso é exclusivo pelos membros competentes que fazem parte de seu corpo social, enquanto a simbólica in- formal consiste no apagamento dessas marcas distintivas.

O campo religioso constitui um exemplo de campo com simbólica formal, uma vez que apenas os membros com posição mais elevada detêm a autorização e a competência para ostentar insígnias e vestes especiais, bem como desempenhar rituais litúrgicos - o que os caracteriza como de competência esotérica. Já o campo midiático expressa-se por uma simbólica informal e competência exotérica, pois destina-se a assegurar, a partir de suas características, a permeabilidade pelos demais campos sociais.

As ações de Malafaia novamente são exemplo: dentro de sua congregação e para seus fiéis (ou seja, no campo religioso), seus discursos baseiam-se nos valores transmitidos pela Bíblia, apoiando-se, portanto, em conhecimentos esotéricos ao campo. Entretanto, quando participa de discussões políticas junto aos parlamentares, à mídia e à sociedade brasileira, são poucos os argumentos ligados à religião. Em seu discurso nesses espaços, o pastor busca legitimidade na Constituição, em estudos de Psicologia (profissão na qual é graduado) e até na Biologia, apoiando-se na permeabilidade da linguagem simbólica exotérica ao campo midiático.

Tais diferenciações são visíveis nos argumentos utilizados pelo pastor (e, com ele, alguns grupos evangélicos e conservadores da sociedade brasileira) no embate com os movimentos LGBTTQIA. O debate teve um de seus pontos altos com o Projeto de Lei da Câmara (PLC) n. 122, proposto em 2006 pela então deputada lara Bernardi, do Partido dos Trabalhadores (PT). O objetivo da proposta era claro: a criminalização de atos discriminatórios ligados a sexualidade e gênero.

Apesar de representar grande avanço na luta dos grupos LGBTTQIA, a 
proposta gerou revolta dos setores mais conservadores da sociedade, que se manifestaram efetivamente em contrariedade à aprovação do Projeto. Malafaia destacou-se por atuar como liderança e como ativista político, fazendo uso de uma ampla rede de discursos e veículos. Promoveu uma grande manifestação em Brasília, recolheu milhares de assinaturas em um abaixo-assinado e exerceu, juntamente com os grupos evangélicos, forte pressão junto aos parlamentares e à imprensa - tudo para impedir que a lei fosse aprovada. Seus principais argumentos foram de que a proposta inibe o direito de expressão dos indivíduos que discordam da prática homossexual e vai contra os valores da Bíblia, da família e da Constituição.

No item seguinte, serão analisadas as postagens nos perfis do pastor no Twitter e no Facebook - mais especificamente durante os anos de 2011 e 2012. Apesar de proposto na Câmara em 2006, foi só cinco anos depois que o Projeto passou a ser discutido no Senado; Malafaia, convidado a participar das audiências públicas de discussão do projeto como líder religioso, foi responsável por ações de grande impacto no desfecho do debate.

\section{Análise das redes sociais de Malafaia}

A escolha pelo Twitter e Facebook definiu-se em função do objetivo geral decompreender a movimentação do pastor e seus seguidores nas redes sociais. A partir dos discursos do pastor, compreendemos como seus fiéis e demais seguidores formulam suas opiniões sobre o tema.

A análise comparativa entre as duas plataformas justifica-se em função de termos observado diferenças significativas na utilização de cada uma pelo pastor. No Facebook, as postagens, além de serem poucas ${ }^{\mathrm{V}}$, não apresentam conteúdo significativo a respeito da opinião de Malafaia sobre o tema. Entretanto, os comentários dos interagentes em seus posts são bastante expressivos e característicos da visão do grupo, bem como da extensão da base de apoio que Silas possui; centramo-nos, então, nesse aspecto. Já no Twitter, o aspecto mais marcante foram os dizeres do próprio pastorVII - que foram, portanto, o foco de nossa observação.Ou seja: enquanto a análise do Facebook tem enfoque na circulação (BRAGA, 2012) dos comentários a partir dos usuários, a do Twitter enfoca na utilização da plataforma como espaço de argumentação e, principalmente, de mobilização pelo próprio pastor. Apesar dessas diferenciações, percebemos algumas utilizações em comum das duas plataformas, tanto por Malafaia quanto por seus seguidores - explanadas em categorias específicas como veremos a seguir.

Além disso, outra observação que se faz importante é com relação ao período de tempo analisado em cada plataforma: no Twitter, coletamos todas as postagens do ano de 2011; no Facebook, como a coleta das postagens deste ano não apresentou conteúdo suficiente para desencadear uma análise significativa, estendemos o período em mais um ano - observando, também, os posts de 2012.

\subsection{Análise do Twitter}

Pode-se considerar o Twitter como uma das maiores armas de Silas na contrariedade ao projeto. Não à toa: o Brasil é o segundo maior do mundo em número de usuários, segundo estudo ${ }^{\text {VIII; }}$; isso explica o interesse do pastor em apropriar-se dele. Além disso, como afirmam Recuero, Zago e Bastos (2014, p. 208), o Twitter diferencia-se das demais redes sociais porque "não funciona apenas como um espaço discursivo de relato, mas também de mobilização". 
Para a análise da movimentação do pastor no ano desejado, utilizou-se o recurso de busca avançada da plataforma, que permite, dentre outras opções, delimitar as postagens por período de tempo. A partir daí, capturamos imagens de todos os tweets do perfil de Malafaia no ano de 2011, fizemos sua divisão em meses e, por fim, em categorias específicas.

A observação dos 871 tweets do ano mostrou que nos meses de maio, junho, julho, outubro, novembro e dezembro, a frequência de postagens foi maior - justamente nos períodos em que Silas mais se empenhou na contrariedade à aprovação do projeto.

Os tweets que fazem referência aos movimentos LGBTTQIA (e, mais especificamente, ao PLC 122) correspondem a cerca de $40 \%{ }^{1 \mathrm{x}}$ de todas as postagens feitas por Malafaia no ano em questão; isso mostra o quanto o pastor empenhou-se em tentar barrar a aprovação do projeto, agindo como um legítimo ativista político. Esses tweets possuem características bem marcantes que permitem diferenciá-los e, logo, categorizá-los. Observou-se:

a) Tweets que fazem chamadas para programas e sites: nesses casos, apenas é feita a referência aos movimentos ou ao PLC; a informação, de fato, está detida em outros veículos que fazem parte da sua rede de atuação midiática. Malafaia convida seus seguidores a acompanharem a discussão nesses outros meios, como em um de seus programas de TV (figura 1), no site da Associação Vitória em Cristo (figura 2) e em um vídeo no Youtube (figura 3).

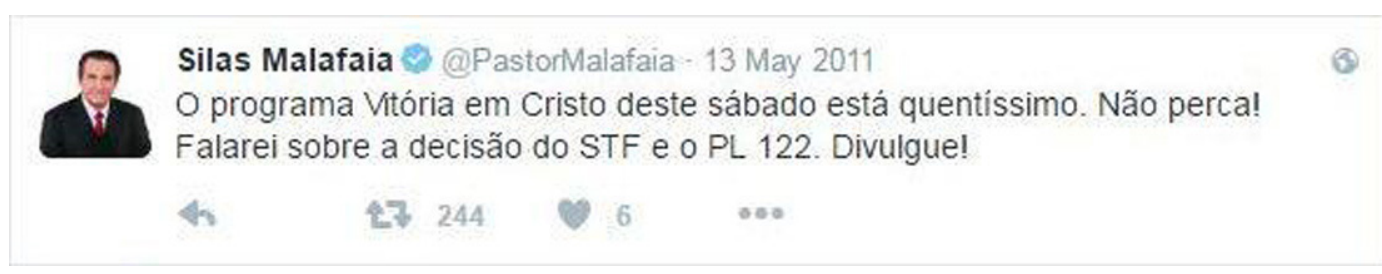

Figura 1: Exemplo de chamada para programa de TV. Fonte: Perfil de Silas Malafaia no Twitter.

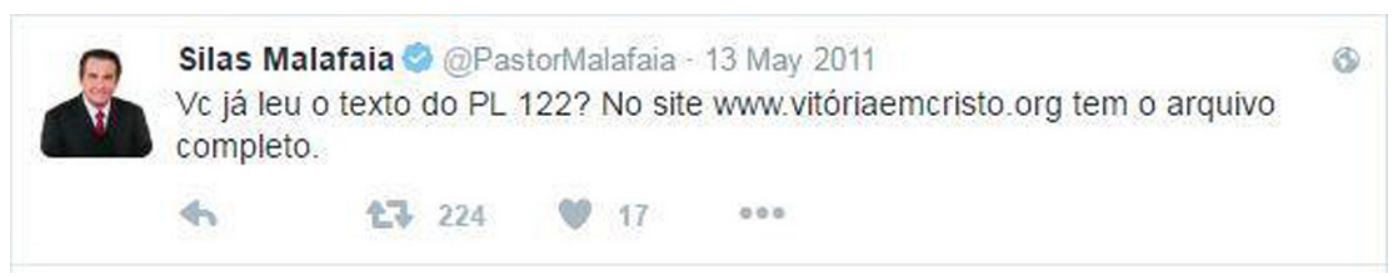

Figura 2: Exemplo de chamada para site. Fonte: Perfil de Silas Malafaia no Twitter.

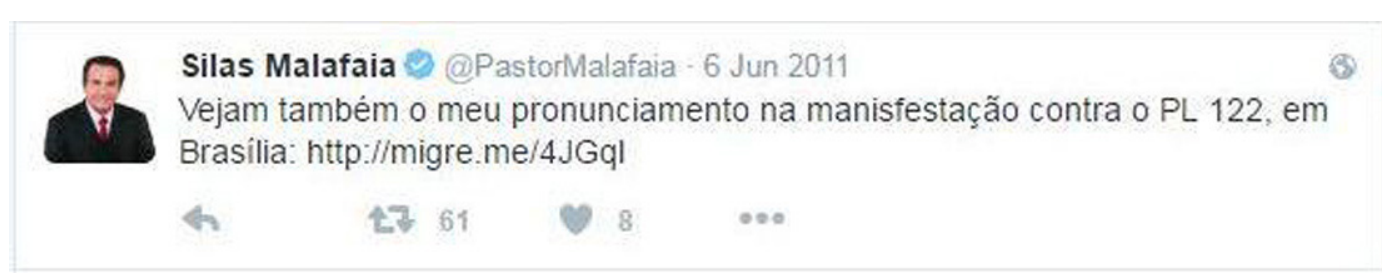

Figura 3: Exemplo de chamada para vídeo. Fonte: Perfil de Silas Malafaia no Twitter. 
b) Tweets de mobilização a respeito do PLC: essa categoria engloba a maior parte das postagens analisadas. Trata-se das mensagens direcionadas exclusivamente aos apoiadores do pastor, convidando-os a manifestarem sua contrariedade ao projeto das mais diferentes formas. Exemplos são o incentivo à participação no abaixo-assinado (figura 4), ao envio de e-mails para os parlamentares participantes das decisões referentes ao projeto (figura 5) e à imprensa, para veicular os argumentos dos grupos discordantes da proposta (figura 6).

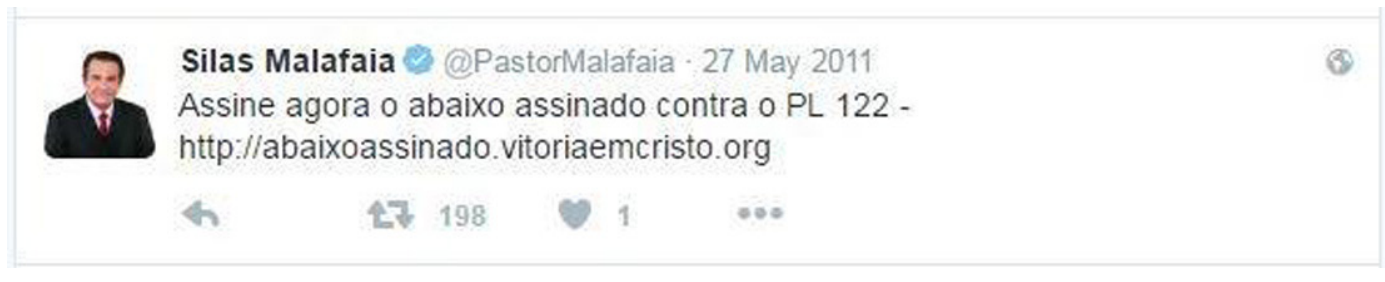

Figura 4: Exemplo de chamada para assinatura. Fonte: Perfil de Silas Malafaia no Twitter.

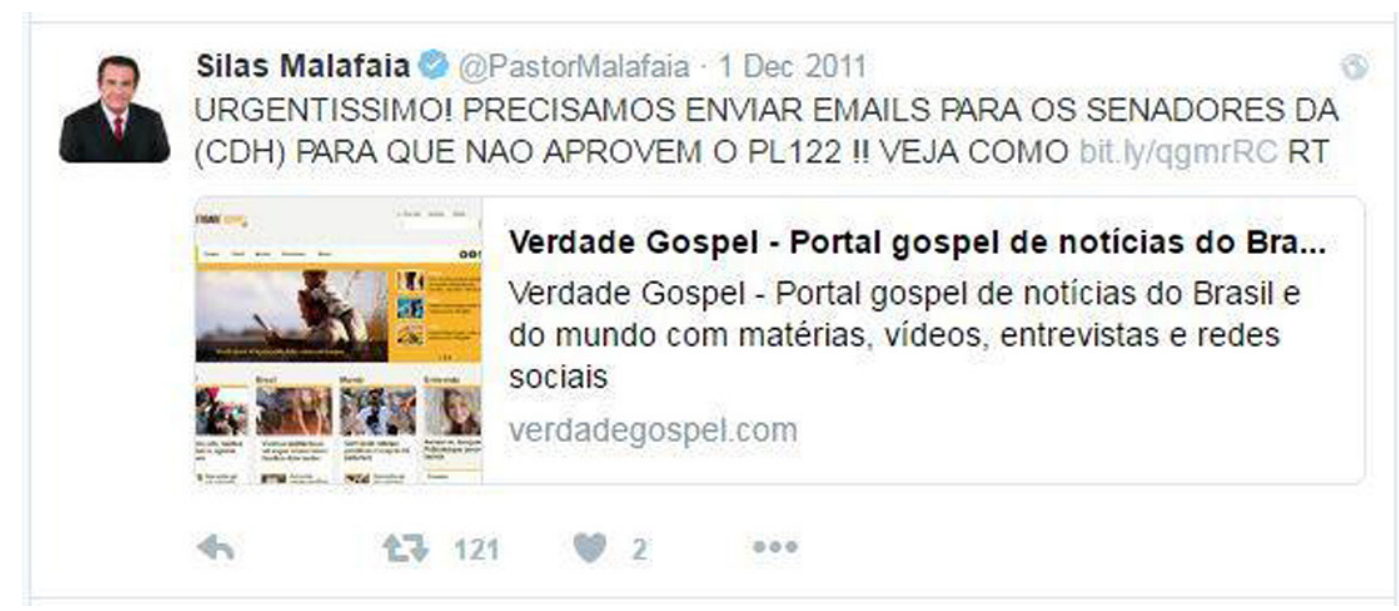

Figura 5: Exemplo de chamada para envio de e-mail a parlamentares. Fonte: Perfil de Silas Malafaia no Twitter.

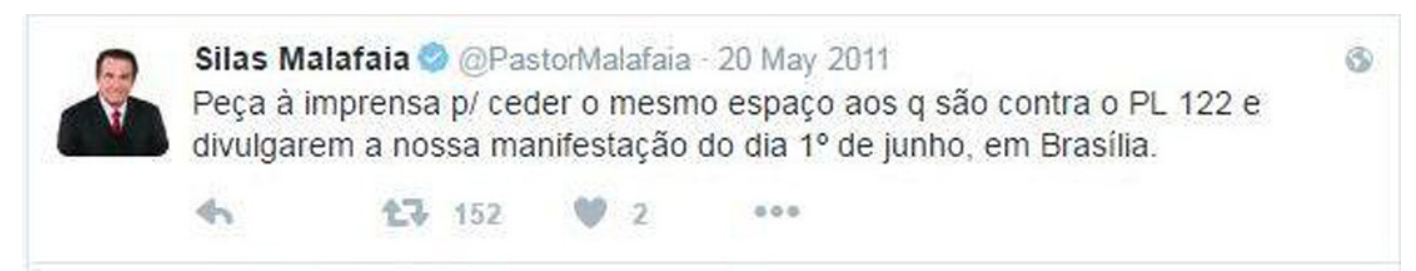

Figura 6: Exemplo de chamada para envio de e-mails à imprensa. Fonte: Perfil de Silas Malafaia no Twitter. 
c) Tweets de feedback dos resultados obtidos: aqui enquadram-se os tweets nos quais o pastor atualiza seus seguidores a respeito da eficácia da campanha, bem como da tramitação do projeto. Na figura 7, por exemplo, Malafaia orgulha-se do número de assinaturas adquiridas no abaixo-assinado; na figura 8 , do número de participantes da manifestação presencial; na figura 9, por fim, Silas informa seus seguidores sobre o andamento do projeto no Senado.

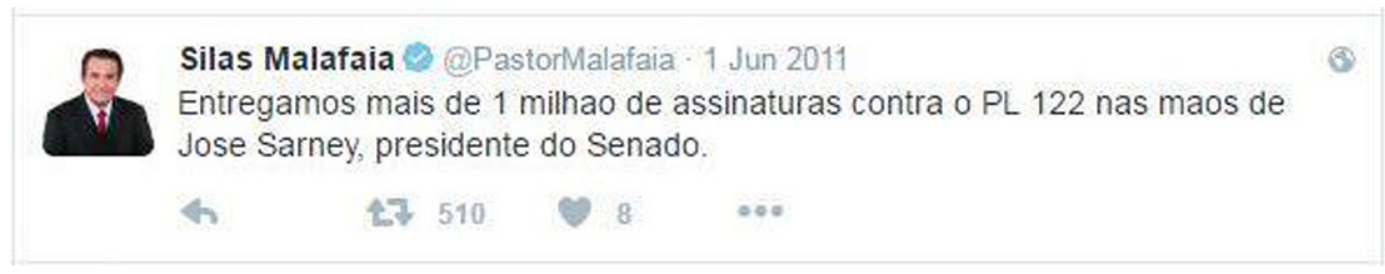

Figura 7: Exemplo de feedback dos resultados. Fonte: Perfil de Silas Malafaia no Twitter.
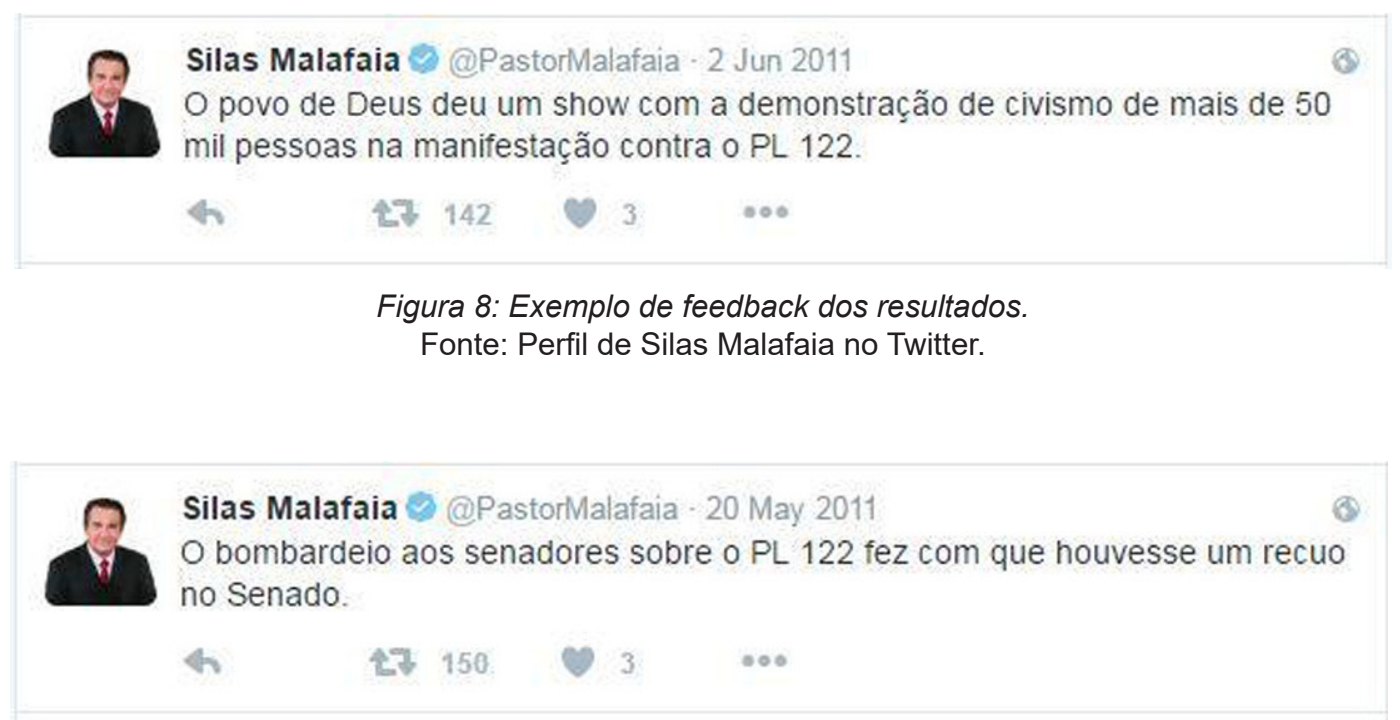

Figura 9: Exemplo de feedback dos resultados. Fonte: Perfil de Silas Malafaia no Twitter.

d) Tweets de justificação do posicionamento: são postagens nas quais Silas defende seu ponto de vista, principalmente a partir de argumentos ligados às suas crenças religiosas e aos seus direitos como cidadão. Encaixam-se aqui, ainda, mensagens direcionadas especificamente aos movimentos LGBTTQIA e esclarecimentos sobre o PLC 122 aos seus seguidores. Pode-se considerar a categoria mais significativa para compreender sua atuação enquanto empreendedor moral.
A figura 10 ilustra vários tweets nos quais Malafaia justifica seus posicionamentos com argumentos como o de que a homossexualidade seria um fator comportamental não-inato, articulando suas ideias a supostos princípios da Psicologia,bem como critica a constitucionalidade do PLC 122 em razão deste supostamente inibir o direito de expressão dos demais cidadãos, aqui justificando-se com argumentos com base no Direito. Chama a atenção, nesses twe- 
ets, a citação do nome deputado federal Jean Wyllys, uma das vozes do movimento LGBTTQIA na Câmara - o que reforça esse contexto de "disputa" entre os dois grupos.

Na figura 11, Silas reforça o argumento de que a homossexualidade vista como um fator comportamental e acrescenta, ainda, que os grupos LGBTTQIA seriam privilegiados caso o projeto fos- se aprovado. A figura 12, por fim, chama a atenção por diferenciar-se das outras duas, já que destaca o interesse religioso na argumentação do pastor. Ele alega não odiar os homossexuais, mas sim suas práticas - das quais, segundo ele, Deus pode "libertá-los". Nesse sentido, identifica-se com a chamada "cura gay", ao explicitar que através da palavra de Cristo, supostamente seria possível um homossexual se tornar heterossexual.

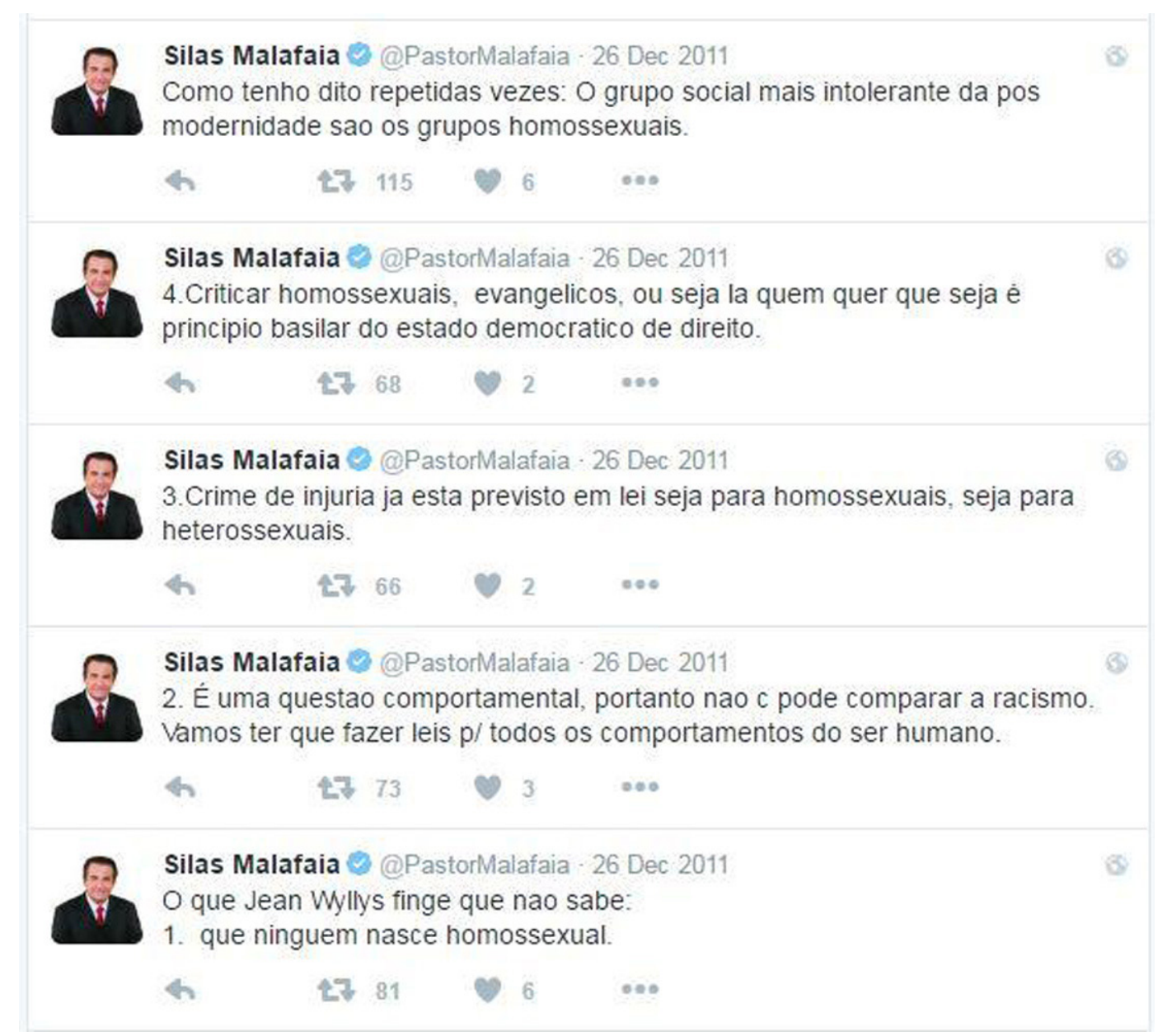

Figura 10: Exemplo ${ }^{x}$ do posicionamento do pastor Fonte: Perfil de Silas Malafaia no Twitter. 


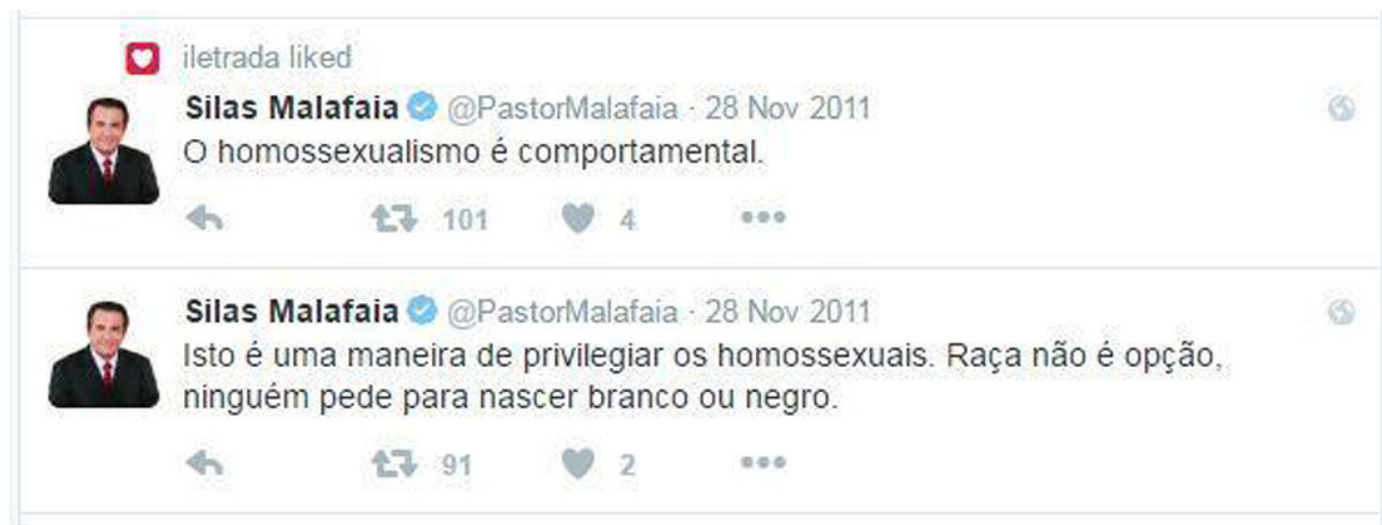

Figura 11: Exemplo do posicionamento do pastor Fonte: Perfil de Silas Malafaia no Twitter.

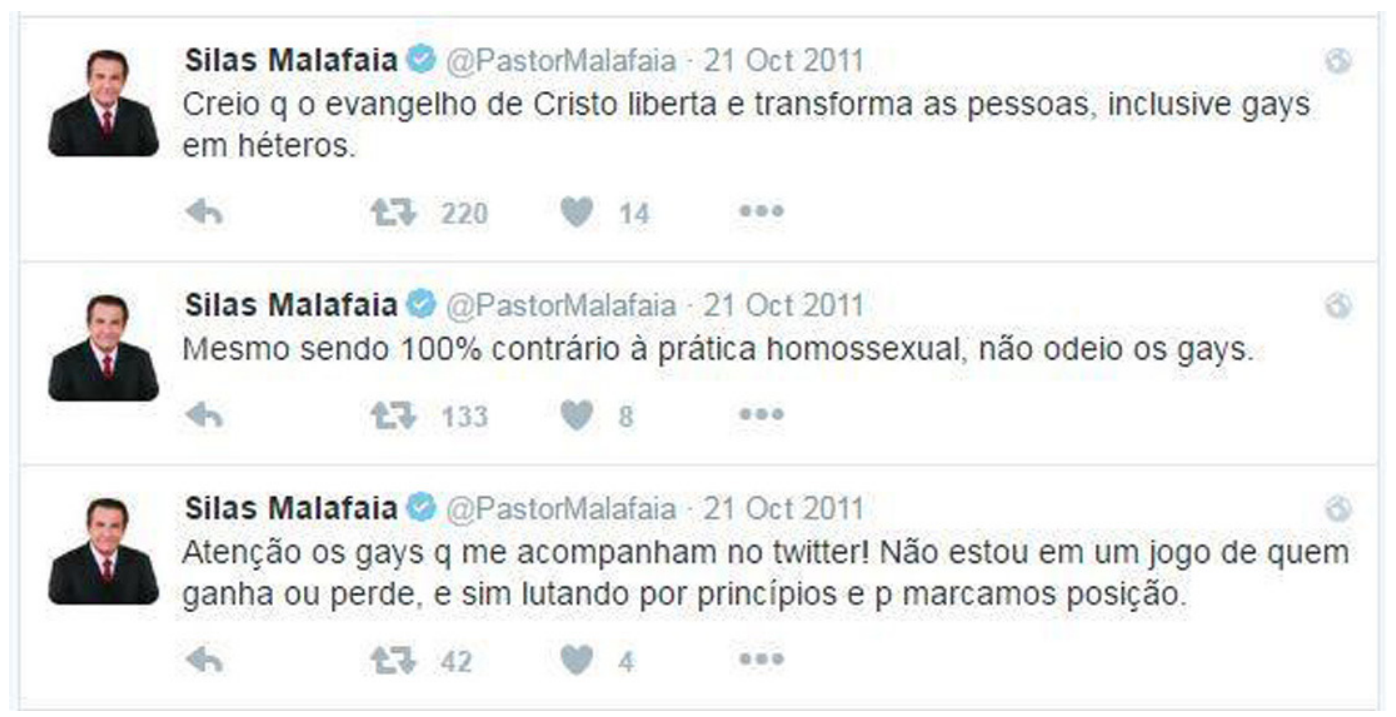

Figura 12: Exemplo do posicionamento do pastor Fonte: Perfil de Silas Malafaia no Twitter.

\subsection{Análise do Facebook}

A coleta feita a partir da página oficial do pastor no Facebook, realizada entre junho de 2011 e junho de 2012, apontou um total de 156 postagens. Entre frases bíblicas, divulgação de eventos e produtos, chamadas para programas, dentre outras, 11 diziam respeito aos embates entre o pastor e seus fiéis e homossexuais.

A maior parte das postagens consiste em frases curtas que levam a outros veí- culos, como seus programas de TV, o Youtube e o site da Revista Veja; não contêm, em si próprias, indícios da visão de Silas a respeito da homossexualidade e do PLC. Já com relação aos comentários, a coleta foi bem mais satisfatória: foram 1294 comentários recolhidos, nos quais se notou uma forte polarização entre os interagentes.

Essa grande carga significativa dos comentários reflete o conceito de circulação trabalhado por Braga (2012). O autor vê o processo de comunicação não mais 
como estático, em que o receptor apenas recebe e assimila a mensagem do emissor, mas sim como "um processo de fluxo contínuo, sempre adiante" (BRAGA, 2012, p. 40).A circulação refere-se, então, aesse amplo "espaço do reconhecimento e dos desvios produzidos pela apropriação" (BRAGA, 2012, p. 38); no caso específico da pesquisa, engloba todos os desdobramentos argumentativos que os discursos que partiram de Malafaia geraram.

Realizamos uma categorização das principais recorrências, selecionando os comentários mais significativos e apontando, assim, a presença de indivíduos apoiadores e contrários ao pastor. a) Indivíduos apoiam o pastor utilizando discursos religiosos: essa categoria caracteriza-se pelo tratamento da homossexualidade como pecado - sendo, por isso, condenada por Deus. Na figura 13, por exemplo, percebe-se a crença no fato de que basear-se na Bíblia Sagrada isenta qualquer indivíduo da acusação de discriminação; na figura 14 , o interagente faz uso de um versículo da Bíblia para justificar o combate à homossexualidade; na figura 15, por fim, o usuário faz referência ao episódio bíblico da destruição da cidade de Sodoma (considerada pecaminosa), comparando o destino de seus moradores ao dos homossexuais.

\title{
[ $=$ só tenho ha dizer que pastor nunca foi homofobico,ele apenas leu o que ta escrito na BIBLIA SAGRADA... 2 de maio de 2012 às $16: 09$ - Curtir . 1 \\ Figura 13: Comentário do interagente 1 Fonte: Página de Silas Malafaia no Facebook.
}

\footnotetext{
outro homem, como se fosse mulher, ambos praticam coisa abominável; serão mortos, o seu sangue cairá sobre eles ).

5 de abril de 2012 às 13:26 - Curtir - 2

Figura 14: Comentário do interagente 2

Fonte: Página de Silas Malafaia no Facebook.
}

\begin{abstract}
Vamos gente criar coragem para expor nossa opinião. NÓS AMAMOS OS GAYS, MAS NÃO CONCORDAMOS COM A PRÁTICA HOMOSEXUAL. ISSO é SODOMISMO e da mesma forma que acabou com Sodoma e as cidades vizinhas, vai acabar como nosso mundo.
\end{abstract}

13 de abril de 2012 às $12: 56$ - Curtir . 2

Figura 15: Comentário do interagente 3

Fonte: Página de Silas Malafaia no Facebook. 
b) Indivíduos que apoiam o pastor utilizando argumentos laicos: são construções discursivas que alegam que os movimentos LGBTTQIA têm o objetivo de impedir que os cristãos usufruam de sua liberdade de expressão, usando expressões como "mordaça" e "censura". Na figura 16, o interagente alega que a prioridade não são os direitos dos homossexuais, mas o exer- cício da liberdade de expressão de quem não concorda com tal prática; o interagente da figura 17 menospreza o movimento homossexual; na figura 18 , percebe-se referência à música "Cálice (cale-se)", de Chico Buarque, utilizada como forma de protesto à repressão durante o Regime Militar. Coloca-se, assim, o PLC 122 como uma forma de censura.

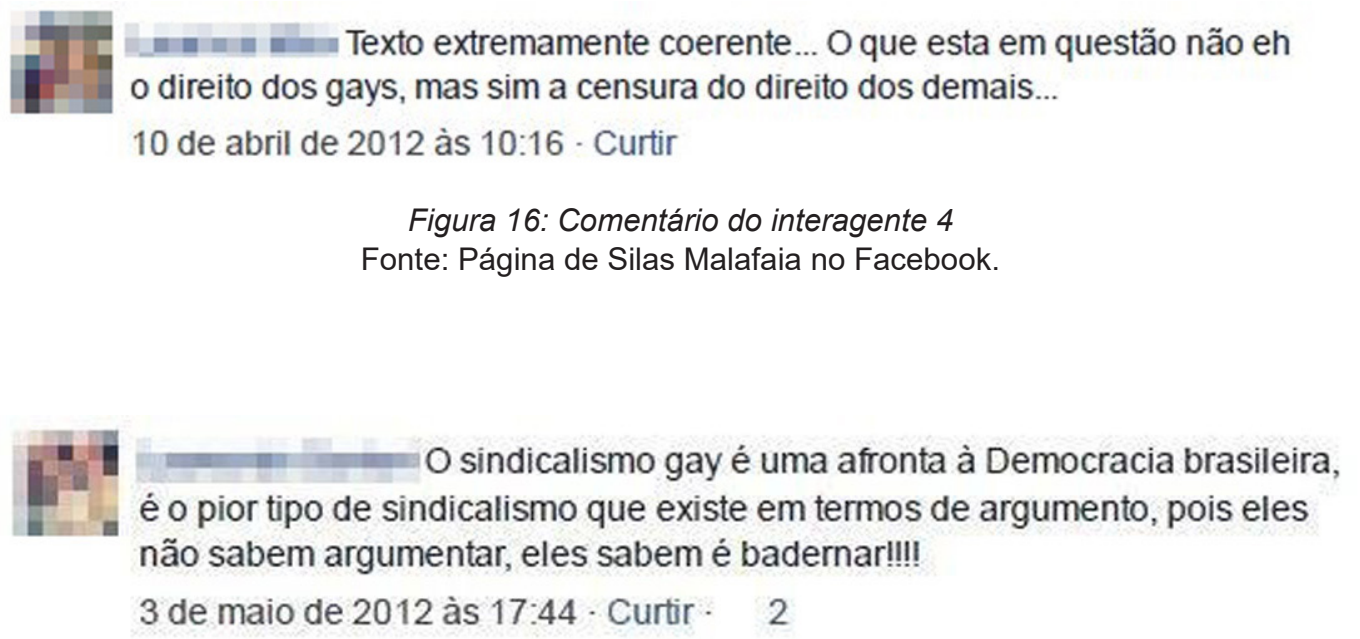

Figura 17: Comentário do interagente 5 Fonte: Página de Silas Malafaia no Facebook.

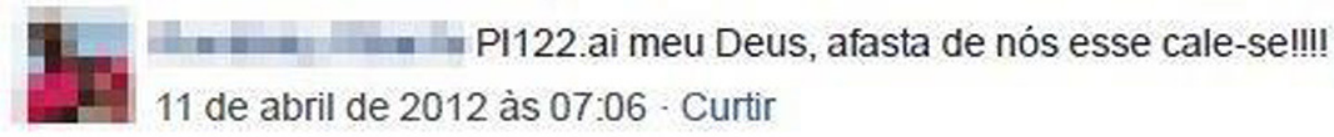

Figura 18: Comentário do interagente 6

Fonte: Página de Silas Malafaia no Facebook.

c) Indivíduos que expressam fé religiosa, mas discordam de Malafaia: tratam-se de argumentos de pessoas dotadas de religiosidade que defendem a disseminação do amor de Cristo e o fim da perseguição aos homossexuais promovida por Malafaia. O interagente da figura 19 critica a postura de Silas e dos demais líderes religiosos envolvidos na causa, alertando os demais fiéis com relação a tais atitudes. Já na figura 20, há uma crítica direta ao pastor: para o interagente em questão, ele devia preocupar-se em pregar a "Palavra de Deus" ao invés de promover tal comoção. 
Povo de Deus! Abram os olhos! O silas e outros líderes estão tirando de vocês a paz que jesus veio trazer. Reflitam.

5 de abril de 2012 às 13:50 - Curtir . 1

Figura 19: Comentário do interagente 7

Fonte: Página de Silas Malafaia no Facebook.

o programa só fala dessas brigas agora? Foram nem 20

minutos de mensagem no outro programa. Menos briga e mais palavra pastor Silas Malafaia

20 de julho de 2011 às $12: 13$ - Curtir . 1

Figura 20: Comentário do interagente 8

Fonte: Página de Silas Malafaia no Facebook.

d) Não-evangélicos que apoiam Silas: casos em que indivíduos de outras vinculações religiosas manifestaram-se a favor do pastor e alegaram concordância com seus argumentos. Na figura 21, um seguidor católico expressa admiração pelo pastor diz fazer parte do grupo dos "católicos convertidos de verdade", concordando com o ponto de vista dele em função de motivos religiosos. No caso da figura 22 , Malafaia recebe apoio de um interagente que se diz ateu, que apresenta concordância no argumento referente à liberdade de expressão. Essa categoria demonstra amplitude das ações do pastor, que atingem não-evangélicos que concordam com seus posicionamentos tanto por motivos laicos quanto religiosos.

\section{Muito bem Pastor Silas... Eu sou católico}

praticante, e saiba que o senhor é muito admirado por todos os católicos convertidos de verdade, parabéns pela coragem... o ser Profeta é assim mesmo: Anunciar o Reino, e denunciar ás injustiças> GRAÇA E PAZ NO SENHOR.

13 de abril de 2012 às $12: 52$ - Curtir - 5

Figura 21: Comentário do interagente 9

Fonte: Página de Silas Malafaia no Facebook.

mesmo sendo ateu eu concordo com isso. É

ridiculo querer proibir alguém de falar sua opiniao

3 de maio de 2012 às $17: 47$. Curtir . 4

Figura 22: Comentário do interagente 10

Fonte: Página de Silas Malafaia no Facebook. 
e) Interagentes que se posicionam contra Malafaia e seus fiéis: são pessoas que se e criticam essa discriminação defendendo que a crença de um grupo não deve afetar o restante da sociedade. Os comentários das figuras 23,24 e 25 assumem-se como membros de grupos LGBTTQIA para refutar as ideias de
Malafaia. $O$ interagente da figura 23 não vê motivo para tal comoção, afirmando que os homossexuais "se amam igual a todos"; na figura 24, há uma crítica à discriminação promovida contra os homossexuais; a interagente da figura 25 alega sentir-se discriminada e dirige-se pessoalmente a Malafaia.

1 Uiiiiiiiii, ele vai fazer denúncias... Sobre o quê? Que a gente se ama igual à todos?! AH, ME POUPE DESTAS SUAS NOJEIRAS! 6 de abril de 2012 às $11: 42$ - Curtir - 1

Figura 23: Comentário do interagente 11 Fonte: Página de Silas Malafaia no Facebook.

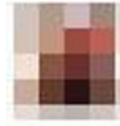

Você gasta a maior parte do seu tempo querendo destruir a dignidade dos gays e ainda quer o nosso silêncio. Os gays não tratam evangélicos como aberração, vocês, ao contrário fazem isso com os gays!!! 7 de julho de 2011 às $17: 18$ - Curtir · 3

Figura 24: Comentário do interagente 12 Fonte: Página de Silas Malafaia no Facebook.

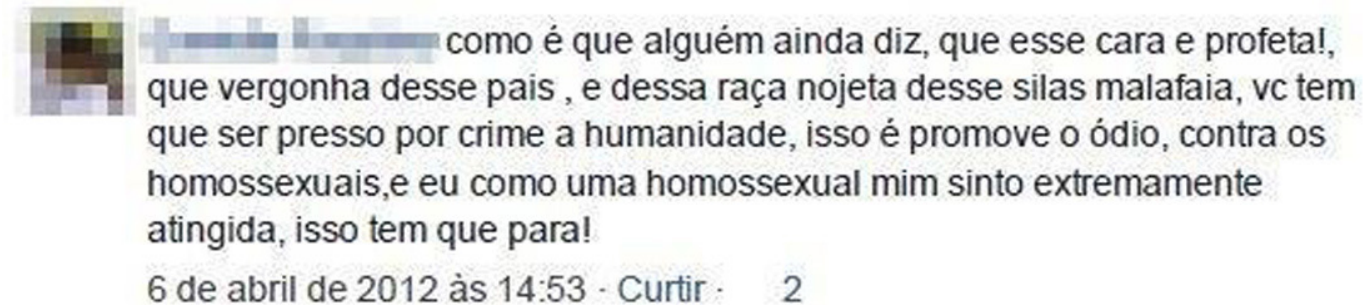

Figura 25: Comentário do interagente 13 Fonte: Página de Silas Malafaia no Facebook.

Já os comentários das figuras abaixo reportam interagentes que não se afirmam como homossexuais, mas argumentam em favor dos grupos LGBTTQIA, defendendo que estes sejam tratados com respeito - sobretudoem função do princípio da laicidadedo Estado. Na figura 26, há menção a fa- tos históricos de perseguição religiosa, comparando-os com o contexto atual; na figura 27 , há reforço do argumento de que a crença de um grupo não deve aplicar-se à sociedade em geral - argumento fortalecido pelo comentário da figura 28, que apela para o princípio de laicidade do Estado. 


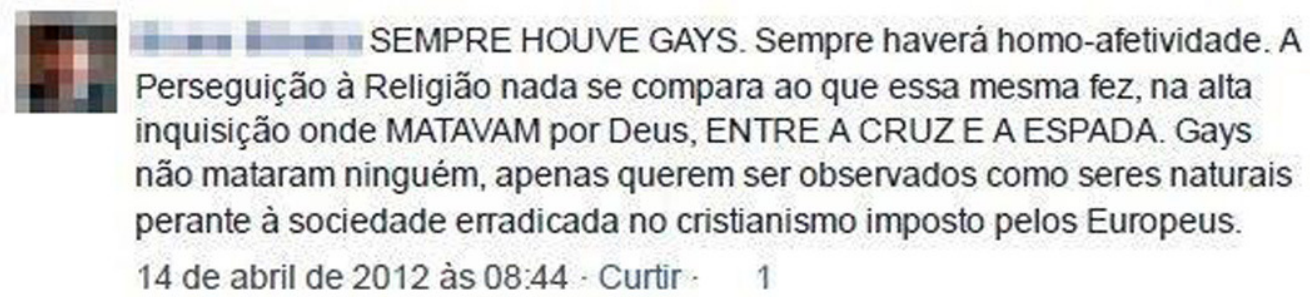

Figura 26: Comentário do interagente 14 Fonte: Página de Silas Malafaia no Facebook.

Hnintiln Se você acha que está falando em nome do deus da sua religião, ótimo pra você. Mas mantenha suas crenças com as pessoas da sua crença, se tal pessoa não segue essa crença ela não é obrigada a escutar os motivos pelos quais ela vai pro inferno. O mundo não gira no seu umbigo $; D$

10 de abril de 2012 às 13:40 - Curtir . 2

Figura 27: Comentário do interagente 15 Fonte: Página de Silas Malafaia no Facebook.

vcs crentes tem que entender que o país é laico e que as pessoas são livres para fazerem suas escolhas...

5 de abril de 2012 às $21: 43$ - Curtir - 3

Figura 28: Comentário do interagente 16 Fonte: Página de Silas Malafaia no Facebook.

Há, ainda, casos em que os comentários são apenas de apoio a Malafaia (sem participação efetiva no debate) - que consistem na maioria dos comentários, mas não são tão significativos em termos de análise discursiva - e, também, inúmeros contendo xingamentos e provocações, de ambos os lados. É perceptível que o debate é acirrado, com os dois grupos tentando defender e justificar sua posição. Também nota-se a repetição de elementos nas falas dos interagentes e, inclusive, deles próprios, que estendem sua participação em discussões acaloradas e provocativas, evidenciando a tensão existente entre os campos religioso e político.

\section{Considerações finais}

Apesar de as postagens do Facebook não apresentarem poucas pistas sobre os argumentos de Malafaia sobre - PLC 122, é possível nesta rede social perceber a força da circulação (BRAGA, 2012) que ocorre a partir de seus discursos. Já a análise do Twitter demonstrou o intenso ativismo político de Malafaia no caso do PLC - visto que foram quase 400 tweets no ano dedicados às suas críticas ao projeto, e, principalmente, à mobilização de seus seguidores em seu favor. A análise transversal das duas redes sociais reportam uma coerência entre os argu- 
mentos explicitados por Malafaia - caracterizados principalmente pela defesa irrestrita da liberdade de expressão e da crítica à prática homossexual a partir de argumentos laicos e religioso - e a circulação dos interagentes, que se alternam entre argumentos laicos e religiosos tanto para criticar como para aderir ao posicionamento de Malafaia.

Sua visão das questões de sexualidade e gênero é evidenciada pelas expressões que utiliza, como "homossexualismo" - termo que não é mais utilizado por tratar a homossexualidade como doença -, "comportamental" - que trata a homossexualidade como opção do indivíduo e não como orientação pré-disposta - e "privilégio", que sugere que os homossexuais ficariam em uma posição superior caso o projeto fosse aprovado. No entanto, observa-se que isso dificilmente ocorreria, uma vez que a população LGBTTQIA é, frequentemente, vítima de discriminação e até agressão no Brasil. Um relatório ${ }^{\mathrm{XI}}$ feito pelo Ministério das Mulheres, da Igualdade Racial e dos Direitos Humanos em 2016 apontou que eram feitas cerca de cinco denúncias diárias ligadas à discriminação sexual e de gênero. Logo, o projeto não visagarantir "privilégios", como afirma o pastor, mas sim de garantir igualdade e justiça para esses grupos.

Apesar dessas formas de tratamento desrespeitosas, o pastor alega "amar os homossexuais". Argumenta que sua contrariedade é apenas à prática homossexual, diferindo opinião de discriminação e criticando fato de que, com a aprovação do projeto, ele e os demais membros do campo religioso que compartilham de seu pensamento não poderiam opinar a respeito do tema sem ser condenados.

Percebe-se, aí, que Malafaia utiliza o seu direito à liberdade de expressão garantido pela Constituição Federal para agir de forma intolerante com relação a essa minoria. Além das expressões que sugerem desconsideração aos grupos LGBTTQIA, a fala do pastor é marcada pelo uso de verbos no imperativo, que demonstram sua posição 'superior' com relação aos movimentos contrários e também aos seus fieis. Reforçam seu papel de liderança e, mais ainda, de empreendedor moral - nesse caso, como impositor de regras.

Para além do empreendedorismo no sentido moral, também percebem-se os aspectos comerciais da atuação do pastor. As estratégias de vinculação do portal Verdade Gospel aos perfis, bem como a divulgação de seus programas de TV refletem a grande variedade de veículos à qual Malafaia é ligado. Sua igreja apresenta níveis de crescimento impressionantes no que se refere a número de membros e concentração de capital econômico, ação que ultrapassa os limites do campo religioso e atinge os demais setores da sociedade - muito em parte por essa intersecção com o campo midiático.

Apesar de o pastor enxergar o ativismo como característica dos movimentos contrários, inclusive denominando os grupos LGBTTQIA envolvidos no debate de "ativistas gays", as atitudes de Silas com relação ao PLC 122 revelaram nele as qualidades de um ativista político e, mais ainda, midiático. Nos meses analisados, Malafaia liderou uma verdadeira cruzada contra projeto,ao lado de grupos religiosos conservadores, alcançando, de certa forma, o efeito desejado: o projeto continua arquivado até hoje.

Esse ativismo também é característica de seus seguidores. Nos comentários, foi possível perceber que as discussões eram prolongadas: os interagentes não só deixavam suas contribuições pessoais, como rebatiam os argumentos de quem pensasse de forma diferente. É significativa a participação de pessoas que não se enquadram como evangélicas, mas con- 
cordam com os dizeres de Silas - prova da extensão de sua base de apoio.

Também é interessante a presença de indivíduos membros e/ou defensores das causas LGBTTQIA, que, assim como o pastor e seus fiéis, utilizam argumentos de várias áreas - do Direito, da Biologia, da História e inclusive da Bíblia, alegando que o objetivo da figura de Jesus é disseminar amor, não ódio.

O pastor mostra-se cada vez mais capaz de mobilizar uma grande massa nas causas de seu interesse, agindo como um verdadeiro líder do campo religioso (BOURDIEU, 2008) e, por fim, como um empreendedor moral (BECKER, 2008) dentro do espaço público social.

\section{Bibliografia}

BECKER, Howard. Empreendedores morais. In: Outsiders: estudos de sociologia do desvio. Rio de Janeiro: Zahar, 2008.

BOURDIEU, Pierre. Gênese e estrutura do campo religioso. In: A economia das trocas simbólicas. São Paulo: Perspectiva, 2007.

BOURDIEU, Pierre. Algumas propriedades dos campos. In: Questões de sociologia. Rio de Janeiro: Marco Zero, 1983.

BRAGA, José Luiz. Circuitos versus campos sociais. In: MATTOS, Maria Ângela; JANOTTI JR, Jeder; JACKS, Nilda (orgs.). Mediação \& midiatização. Salvador: EDUFBA; Brasília: Compós, 2012.

BRASIL JÁ É o segundo país em número de contas no Twitter | InfoBrasil. Disponível em: <https:// www.infobrasil.inf.br/noticia/brasil-ja-e-o-segundo-pais-em-numero-de-contas-no-twitter>. Acesso em 7 de abril de 2017.

CAMPOS, Leonildo. Protestantismo brasileiro e mudança social. In: SOUZA, Beatriz; MARTINO, Luís Mauro (orgs.). Sociologia da religião e mudança social: católicos, protestantes e novos movimentos religiosos no Brasil. São Paulo: Paulus, 2004.

CAMPOS, Renata; GUSMÃO, Eduardo; MAURICIO JR., Cleonardo. A disputa pela laicidade: uma análise das interações discursivas entre Jean Wyllys e Silas Malafaia. Religião e Sociedade, v. 35, n. 2, p. 165-188, 2015.

CUNHA, Magali. A interseção mídia religiosa e mercado e a ressignificação de signos bíblicos pelos evangélicos. RelegensThréskeia, v. 3, n. 1, p. 1-23, 2014.

CUNHA, Magali. O lugar das mídias no processo de construção imaginária do "inimigo" no caso Marco Feliciano. Comunicação, Mídia e Consumo, v. 10 , n. 10 , p. 51-74, 2013.

CUNHA, Magali. Audiência, mercado, política e poder: chaves teórico-interpretativas da intensa aproximação das Organizações Globo com o segmento evangélico no Brasil. In: MOREIRA, A. et al. Anais do VII Congresso Internacional em Ciências da Religião. Programa De Pós- Graduação Em Ciências Da Religião, PUC Goiás, Goiânia, 08 a 11 de abril de 2014. Anais...

DECLARAÇÃO DOS DIREITOS HUMANOS (1948), ONU. Disponível em:<http://www.dudh.org. br/wp-content/uploads/2014/12/dudh.pdf>. Acesso em 13 de julho de 2016.

FELICIANI, Márcia; DALMOLIN, Aline. Silas Malafaia e os Direitos LGBT: Uma Análise das Interações na Página do Pastor no Facebook. In: Anais do XXXIX Congresso Brasileiro de Ciências da Comunicação. Intercom - Sociedade Brasileira de Estudos Interdisciplinares da Comunicação, USP, São Paulo, SP, 05 a 09 de setembro de 2016. Anais...

FELICIANI, Márcia; DALMOLIN, Aline. A Mobilização de Silas Malafaia no Twitter Contra o PLC 122 (Lei Anti-Homofobia). In: Anais do XVIII Congresso de Ciências da Comunicação na Região Sul. Intercom - Sociedade Brasileira de Estudos Interdisciplinares da Comunicação, UCS, Caxias do Sul, RS, 15 a 17 de junho de 2017. Anais...

FOUCAULT, Michel. A arqueologia do saber. Rio de Janeiro: Forense Universitária, 2008.

IBGE: catolicismo cai $22,4 \%$ e vê nova ascensão de evangélicos. Disponível em: <https://noticias. terra.com.br/brasil/ibge-catolicismo-cai-224-e-ve- 
-nova-ascensao-de-evangelicos,7c9ddc840f0da3 10VgnCLD200000bbcceb0aRCRD.html>. Acesso em 07 de abril de 2017.

MAIA, Eduardo. Os evangélicos e a política. Em tese - Revista eletrônica dos pós-graduandos em Sociologia Política da UFSC, v. 2, n. 2, p. 91-112, 2006.

RECUERO, Raquel; ZAGO, Gabriela; BASTOS, Marco. O discurso dos \#ProtestosBR: análise de conteúdo no Twitter. Galaxia, n. 28, p. 199216, dez. 2014.

RODRIGUES, Adriano Duarte. Experiência, modernidade e campo dos media. In: SANTANA, R. M. (org.). Reflexões sobre o mundo contemporâneo. Rio de Janeiro: Revan; Teresina: Universidade Federal do Piauí, 2000.

VIOLÊNCIA HOMOFÓBICA: Brasil tem 5 denúncias por dia, mas números reais são muito maiores, diz relatório. Disponível em: <http:// www.huffpostbrasil.com/2016/02/26/relatorio-homofobia_n_9330692.html>. Acesso em 7 de abril de 2017 .

\section{Recebido em 31/07/2017 Aprovado em 30/08/2017}

I Márcia Zanin Feliciani. Universidade Federal de Santa Maria / UFSM (RS, Brasil). Contato: marciazaninfeliciani@gmail.com

II Leandra Cohen Schirmer. Universidade Federal de Santa Maria / UFSM.

III Aline Roes Dalmolin. Doutora e mestre em Ciências da Comunicação pela Universidade do Vale do Rio dos Sinos / Unisinos (RS, Brasil). Professora da Universidade Federal de Santa Maria / UFSM (RS).

IV Disponível em https://www.terra.com.br/noticias/ brasil/ibge-catolicismo-cai-224-e-ve-nova-ascensao-de-evangelicos,7c9ddc840f0da310VgnCLD200000bb cceb0aRCRD.html.
$\mathrm{V}$ Lésbicas, gays, bissexuais, transexuais, travestis, queer, interssexuais e assexuados.

VI Acredita-se que isso se deve, em parte, ao fato de que a plataforma não era tão utilizada na época como é hoje.

VII A observação enfocou a argumentação do pastor, também, devido à dificuldade de análise das interações na plataforma.

VIII Disponível em: https://www.infobrasil.inf.br/noticia/brasil-ja-e-o-segundo-pais-em-numero-de-contas-no-twitter.

IX Cálculo feito a partir da comparação do número total de tweets com o número de referências ao grupo em questão. Esse último foi resultado da contagem manual das postagens, caracterizadas, especialmente, pelo uso de expressões como "homossexuais", "gay", "PL 122", "manifestação", "abaixo-assinado" etc.

X A ordem cronológica dos tweets é contrária à forma apresentada, devido à lógica da plataforma.

XI Disponível em http://www.huffpostbrasil. com/2016/02/26/relatorio-homofobia_n_9330692. html. 